\title{
Poly(2-oxazoline)s: A comprehensive overview of polymer structures and their physical properties
}

Mathias Glassner, Maarten Vergaelen and Richard Hoogenboom*

Supramolecular Chemistry Group, Department of Organic and Macromolecular Chemistry, Ghent University, Krijgslaan 281-S4, 9000 Ghent, Belgium. Richard.Hoogenboom@ugent.be

\begin{abstract}
Poly(2-oxazoline)s (PAOx) are of increasing importance for a wide range of applications, mostly in the biomedical field. This review describes the synthesis of 2-oxazoline monomers, their cationic ring-opening polymerization (CROP) and gives a comprehensive overview of all reported PAOx homopolymers. In the second part of the review, the polymer properties of these PAOx homopolymers with varying side-chain structures are discussed. Altogether, this review intends to serve as encyclopedia for poly(2-oxazoline)s enabling the straightforward selection of a polymer structure with the desired properties for a certain application.
\end{abstract}

Keywords: Poly(2-oxazoline)s, cationic ring-opening polymerization, thermal properties, mechanical properties, surface properties, solution properties Graphical abstract: 


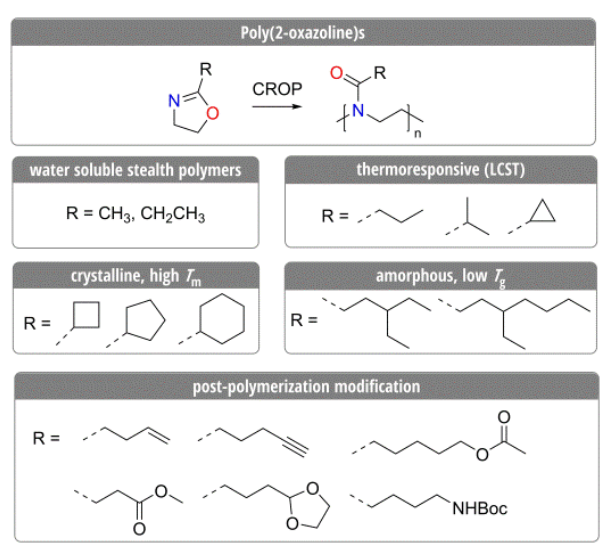




\section{Introduction}

Over the years numerous 2-oxazolines have been used in the cationic ring-opening polymerization (CROP) to obtain the corresponding poly(2-oxazoline)s (PAOx, also referred to as POx, POz), since 1966, when they were reported for the first time by four independent research groups. ${ }^{1-4}$ Besides their use as monomers, 2-oxazolines are also commonly used as ligands in asymmetric catalysis. ${ }^{5-7}$ In the last decade PAOx have received increasing interest, especially for biomedical applications. Several reviews on this topic have recently been published providing an excellent overview of the current state-of-the-art. ${ }^{8-14}$ Even though the application potential of PAOx is tremendous and has been the focus of many review articles, it is relatively difficult to get a complete overview of the different PAOx structures that have been reported as well as a systematic insight in the properties of the different PAOx.

Therefore, the present review aims to provide a comprehensive overview of PAOx homopolymers. The review will start with a brief overview of the different methods to synthesize 2-oxazoline monomers and the CROP mechanism leading to PAOx. The second part of the review comprises an as complete as possible overview of all reported 2-oxazoline monomers that have been polymerized via CROP followed by sections discussing the thermal, mechanical, surface and solution properties of the resulting PAOx homopolymers. We hope that this review will serve as guide for the selection of a specific PAOx for various future applications.

\section{Synthesis of 2-oxazoline monomers}

Except for some 4- and 5-substituted 2-oxazolines, which are not always polymerizable, ${ }^{15-18}$ 2-substituted 4,5-dihydrooxazoles, i.e. 2-substituted-2-oxazolines, referred to as 2-oxazolines in the following paragraphs, are the most commonly used cyclic imino ether monomers in 
CROP. Typically 2-oxazolines are synthesized via the direct synthesis from non-activated carboxylic acids, ${ }^{19}$ the Witte-Seeliger synthesis from nitriles ${ }^{20,21}$ or the Wenker method ${ }^{22}$, i.e. a two-step synthesis via cyclization of $\beta$-halo amides (see scheme 1). Other less common synthesis routes, e.g. $\alpha$-deprotonation of 2-methyl-2-oxazoline followed by alkylation towards more complex 2-oxazolines, are also reported. ${ }^{23,}{ }^{24}$ For a more detailed overview and description of the synthesis of 2-oxazolines one can refer to the recent review by Verbraeken et $a .^{25}$

1.<smiles>[R]C(=O)O</smiles>

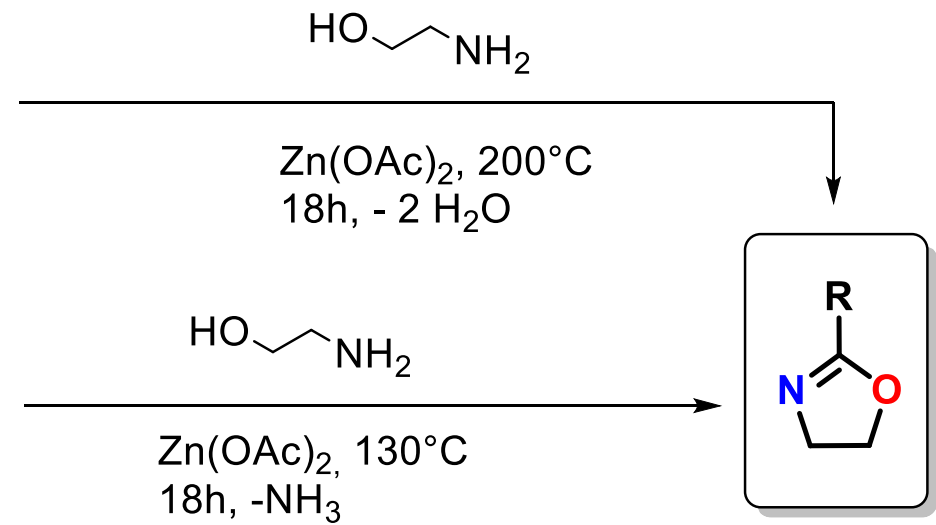

3.<smiles>[R]C(=O)Cl</smiles>

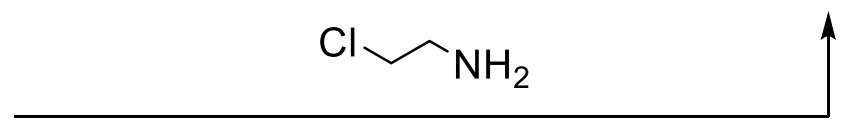

1. $\mathrm{Et}_{3} \mathrm{~N}, \mathrm{CH}_{2} \mathrm{Cl}_{2}$ (dry), $0^{\circ} \mathrm{C}, 24 \mathrm{~h}$

2. $\mathrm{KOH}$ or $\mathrm{Na}_{2} \mathrm{CO}_{3}(0.9 \mathrm{eq}),-\mathrm{HCl}$

Scheme 1. Overview of the synthesis of 2-oxazolines monomers. 1. Direct synthesis via non-activated carboxylic acids, 2. The Witte-Seeliger method starting from nitriles and 3. The (modified) Wenker method.

\section{Cationic ring-opening polymerization of 2-oxazolines}

The first CROP of 2-oxazolines was reported 50 years ago by four independent research groups, resulting in a new class of polymers, i.e. the PAOx. ${ }^{1-4}$ The CROP mechanism consists of three steps, initiation, propagation and termination (scheme 2). 


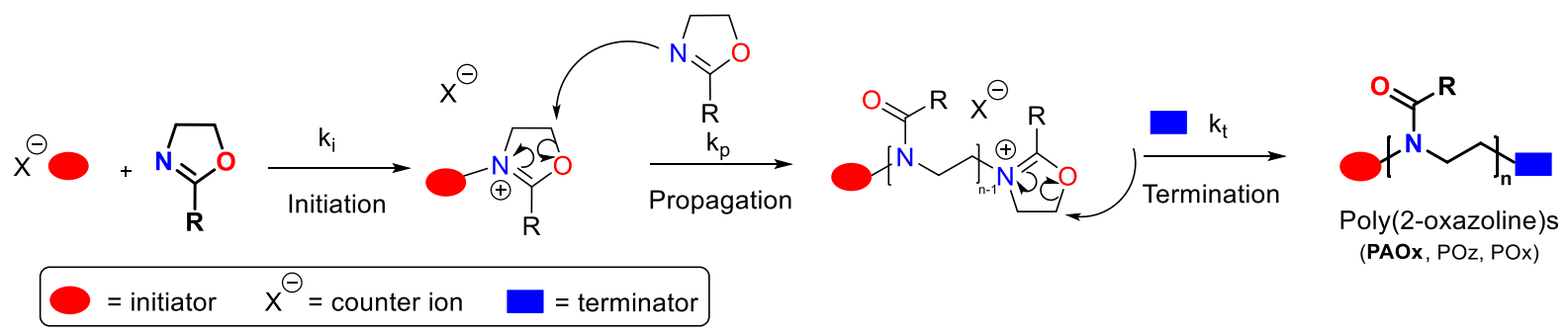

Scheme 2. The cationic ring-opening polymerization of 2-oxazolines, three-step mechanism with initiation, propagation and termination step.

In the first step a nucleophilic attack of the nitrogen lone pair of the 2-oxazoline monomer onto an electrophilic initiator forms an oxazolinium cation, initiating the polymerization reaction. Different initiator systems can be used including alkyl sulfonates such as methyl $p$-toluenesulfonate (MeOTs), which is most frequently found in literature, p-nitrobenzenesulfonates (nosylates) and trifluoromethanesulfonates (triflates), alkyl, benzyl and acetyl halides, oxazolinium salts and lewis acids. ${ }^{26-34}$ Also functional initiators can be used as long as they don't bear any nucleophilic character that could interfere with the CROP. An overview of various functional initiators that have been reported can be found in a review by Lapinte et $a .^{35}$

Subsequently, in the propagation step the 2-oxazoline monomer attacks the cationic oxazolinium intermediate, forming the poly(2-oxazoline) backbone by ring-opening and the formation of an amide while remaining the living oxazolinium chain-end. In an ideal polymerization no chain coupling, transfer or termination reactions occur resulting in the living character of the CROP of 2-oxazolines. The livingness of the polymerization results in control over molecular weight and narrow molar mass distribution, i.e. dispersity ( $\oslash)$, if the initiation is fast and quantitative. Unfortunately chain transfer reactions, such as $\beta$-elimination, and coupling reactions have been reported, which become especially important when aiming for high molar mass PAOx. ${ }^{36-40}$ A detailed overview of the CROP mechanism and chain transfer mechanism can be found in a recent review by Verbraeken et al. ${ }^{41}$ Furthermore, 
the synthesis of well-defined PAOx with a narrow molar mass distribution requires thorough purification of the initiator, monomer and solvent used for the polymerization, to avoid the presence of nucleophilic impurities, including traces of moisture, that induce chain transfer and termination reactions. A recent patent, by Monnery et al., shows the ability of synthesizing defined high molar mass poly(2-oxazoline)s by excluding these side reactions under critical reaction conditions, including specialized vacuum techniques and low temperature polymerization. ${ }^{42}$

Finally, termination of the CROP of 2-oxazolines occurs via nucleophilic attack of an added termination agent on the living cationic chain-end. Most strong nucleophiles, such as methanolic potassium hydroxide, carboxylates and amines, can be used to terminate the polymerization reaction onto the 5-position of the activated 2-oxazoline ring (scheme 3). Termination on the 2-position - where the side-chain is located - has also been reported for other, weaker nucleophiles, particularly water as most important example. ${ }^{43,44}$ With the CROP being a living/controlled polymerization mechanism, functionalities can be easily introduced upon termination with high end-group fidelity.

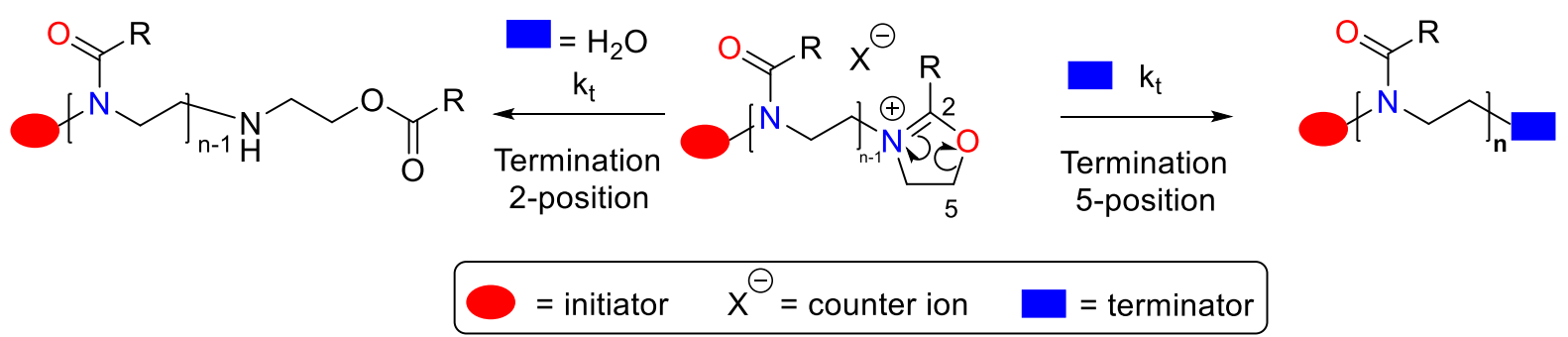

Scheme 3. Example of termination reaction respectively on the 2-position, e.g. with water, and on the 5-position of the oxazolinium chain-end.

Oxygen, nitrogen, sulfur and carbon centered nucleophiles, which exclusively terminate via reaction at the 5-position, can be used to introduce functional groups at the $\omega$-chain-end as illustrated in table 1. 


\section{Poly(2-oxazoline) homopolymers}

In the last 50 years an enormous range of PAOx with varying side-chain structures has been reported in the literature. Tables 1-6 provide a comprehensive overview of all reported 2oxazoline monomers whose respective PAOx homopolymers have been prepared by CROP. The simplest and most widely studied PAOx are those with linear or branched alkyl side-chain (Tables 2 and 3). Table 4 shows reported 2-oxazolines with a phenyl or benzyl substituent. The propagation rate constants $\left(k_{\mathrm{p}}\right.$; strictly speaking apparent $k_{\mathrm{p}}$ 's are listed as on information is provided on percentage of cationic propagating species (close to $100 \%$ with methyl tosylate) nor initiation efficiency) of 2-alkyl-2-oxazolines decrease with an increase of the inductive electron donating character of the 2-substituent. Therefore $k_{\mathrm{p}}$ decreases in the order $\mathrm{MeOx}>$ EtOx $>i$-PrOx. It is noteworthy that an increase of the side chain length for linear alkyl chains from ethyl to $n$-nonyl has a minimal influence on the $k_{\mathrm{p}} .{ }^{83}$ Amongst 2-oxazolines with a propyl side-chain $k_{\mathrm{p}}$ decreases in the order $c$-PrOx $>n$-PrOx $>i$-PrOx. ${ }^{84}$ The CROP of 2-aryl-2oxazolines is generally slower compared to 2-alkyl-2-oxazolines. Electron withdrawing parasubstituents such as $\mathrm{Cl}$ or $\mathrm{NO}_{2}$ slightly increase the $k_{\mathrm{p}}$ of 2-phenyl-2-oxazoline derivatives which can be explained by an increased reactivity of the cationic propagating species. ${ }^{85} \mathrm{An}$ exception to this general trend are ortho-fluoro substituted PhOx, whereby 2,6-DFOx is the fastest 2-oxazoline monomer in the living CROP reported to date. ${ }^{86}$ This acceleration of the CROP of orthofluoro substituted PhOx is due to loss of the conjugation by out of plane twisting of the aryl substituent.

An important feature of PAOx is that functional groups can easily be incorporated in the polymer side-chains by employing functional monomers. The 2-oxazolines with a group 15 ( $\mathrm{N}$ or $\mathrm{P}$ ) or group $16(\mathrm{O}$ or $\mathrm{S})$ heteroatom in the substituent that have been used for CROP are collected in Tables 5 and 6 respectively. It should be noted that for some of these monomers 
the polymerization conditions have to be selected more carefully than for simple 2-alkyl-2oxazolines. The monomers with a Boc protected amino group (C4NHBocOx) could only be polymerized using an oxazolinium salt as initiator while the use of methyl triflate resulted in the formation of undefined low molar mass products. ${ }^{127}$ Monomers with cyclic amines can be polymerized via the CROP mechanism yielding the corresponding PAOx with initiators such as methyl tosylate or methyl triflate resulting in a cationic propagating species, with the risk of termination by attack of the living chain end on the tertiary amine group. However initiators such as benzyl chloride, or methyl iodide result in covalent propagation that gives rise to a double isomerization ring-opening polymerization yielding polymers with a completely different structure having a cyclic urea in the main chain. ${ }^{128,} 129$ The CROP of the diethyl phosphonate functional monomer PhosOx gives polymers with two distinct molar masses. The underlying mechanism for this is not yet understood. ${ }^{130}$ All the thioether containing monomers were found to show a limited polymerizability. Only well-defined polymers of relatively low molar mass could be obtained by keeping the conversion low, which could be due to attack of the sulfur on the propagating oxazolinium species resulting in termination and chain-transfer. ${ }^{99}{ }^{131}$ Similarly, the CROP of FuOx yielded a poorly defined polymer ascribed to unknown interfering side reactions. ${ }^{99}$

The choice of monomers is only limited by the incompatibility of nucleophilic reactive groups, such as hydroxyls, amines, aldehydes, thiols and carboxylic acids, with the CROP process. However, PAOx with these functional groups can be prepared by the CROP of protected monomers followed by post-polymerization deprotection as shown in Scheme 4. 
<smiles>CC(C)(C)CNCCCCCCC(=O)OC(C)(C)C</smiles>

$m=3$ or 4<smiles>COC(=O)CCCC(C)C(=O)OCC(C)(C)C</smiles>

$\mathrm{m}=1$ or 20<smiles>CCOC(=O)OCCN(C)C(=O)CCC(C)CO</smiles>

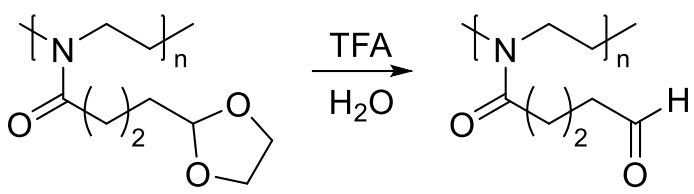<smiles>COc1ccc(CSCCC(=O)N(C)CC(C)(C)C)cc1</smiles>

Scheme 4. Synthesis of PAOx with amino, carboxy, hydroxyl, aldehyde and thiol groups in the sidechains by post-polymerization deprotection. For references see the respective entries in tables 4 and 5. The synthesis of PAOx with thiol side-chains has only been reported for copolymers with EtOx. TFA $=$ trifluoroacetic acid.

Table 7 shows 2-oxazolines with perfluoroalkyl substituents which can be used for the preparation of very hydrophobic PAOx. 2-Perfluoroalkyl-2-oxazolines were found to be much less reactive than 2-alkyl-2-oxazolines and therefore difficult to polymerize. Well-defined polymers of relatively low molar mass could only be obtained by using methyl triflate as initiator and not with methyl tosylate or methyl $p$-nitrobenzene sulfonate. ${ }^{147}$ This limitation can be overcome by the introduction of an ethyl spacer between the 2-oxazoline ring and the perfluoroalkyl group to decouple the electron withdrawing effect of the perfluoralkyl chain from the 2-oxazoline ring. ${ }^{98}$ 


\section{Thermal properties of poly(2-oxazoline) homopolymers}

PAOx with hydrocarbon side-chains are stable up to temperatures of (at least) $300{ }^{\circ} \mathrm{C}^{87,117}$ enabling applications over a broad temperature range. Poly(2-n-alkyl-2-oxazoline)s with varying length of the side-chains are ideal to study structure-property relationships. Figure 1 shows the glass transition temperatures $\left(T_{\mathrm{g}}\right)$ and melting temperatures $\left(T_{\mathrm{m}}\right)$ obtained from differential scanning calorimetry (DSC) of poly(2-n-alkyl-2-oxazoline)s with 1-17 carbon atoms in the side-chain.

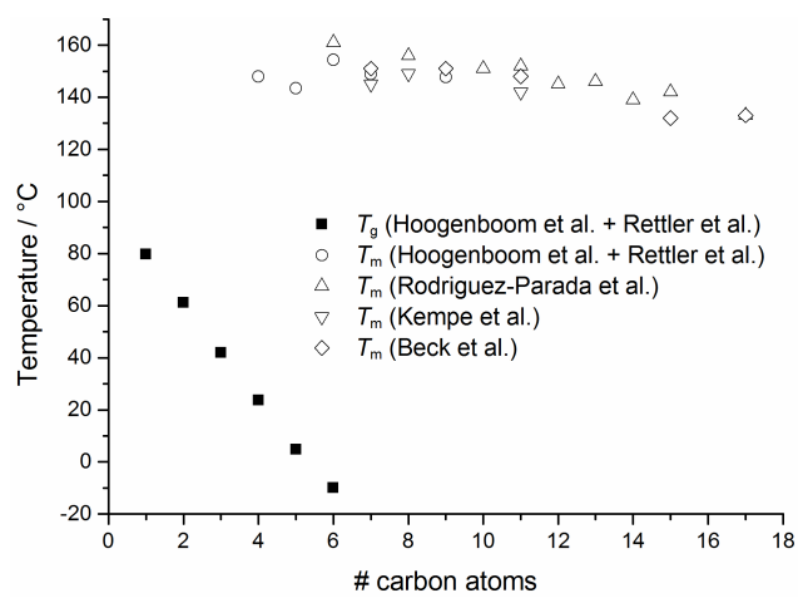

Figure 1. Glass transition and melting temperatures of poly(2-n-alkyl-2-oxazoline)s with varying sidechain length obtained from DSC. Data are taken from refs. 19, 83, 89, 98,99

Polymers with 1-5 carbon atoms in the side-chain (PMeOx to Pn-PentOx) show a $T_{\mathrm{g}}$ that decreases linearly with increasing side-chain length which can be explained by increasing flexibility of the side-chains. For PMeOx, PEtOx and Pn-PrOx no melting peaks were observed by differential scanning calorimetry, while polymers with 4 or more carbon atoms in the sidechain were found to be semi-crystalline with a $T_{\mathrm{m}}$ around $150^{\circ} \mathrm{C}$ independent of the side-chain length indicating side-chain crystallization. In contrast, Litt and co-workers ${ }^{3}$ reported melting temperatures also for PMeOx and Pn-PrOx by differential temperature analysis (DTA) based on a difference in birefringence. This discrepancy might originate from different processing resulting in alignment of the main-chains if enough time is given. ${ }^{150,151}$ The fatty-acid based 
PSoyOx revealed a much lower $T_{\mathrm{m}}\left(88.4^{\circ} \mathrm{C}\right)$ than PAOx with long linear saturated alkyl sidechains due to the cis-double bonds in the side-chains that disturb the crystallization. ${ }^{103}$ Fully amorphous PAOx with a low $T_{\mathrm{g}}$ can be prepared using monomers with branched alkyl sidechains as demonstrated for PEPox, P3EPOx and PEHOx (Scheme 5), the latter being the amorphous poly(2-oxazoline) with the lowest reported $T_{\mathrm{g}}$ to date, being $-6^{\circ} \mathrm{C}$.

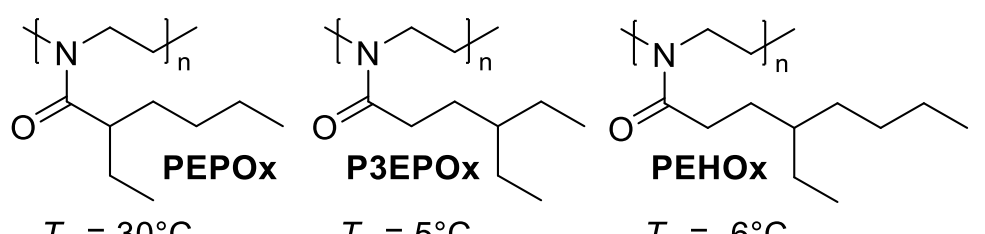

$$
T_{\mathrm{g}}=30^{\circ} \mathrm{C} \quad T_{\mathrm{g}}=5^{\circ} \mathrm{C} \quad T_{\mathrm{g}}=-6^{\circ} \mathrm{C}
$$

Scheme 5. Structures and $T_{\mathrm{g} S}$ of PEPOx, P3EPOx and PEHOx.

PAOx with cycloalkyl side-chains are an interesting class of polymers. While Pc-PrOx is amorphous with a higher $T_{\mathrm{g}}\left(79^{\circ} \mathrm{C}\right)$ than its linear analogue $\mathrm{P} n$-PrOx $,{ }^{115} \mathrm{Pc}-\mathrm{BuOx}, \mathrm{Pc}$-PentOx and $\mathrm{Pc}-\mathrm{HexOx}$ are semi-crystalline high performance polymers with a $T_{\mathrm{m}}$ of 243,251 and $306^{\circ} \mathrm{C}$, respectively..$^{117}$ Similarly high melting points have been reported for adamantylcontaining PAOx. ${ }^{118}$ Poly(2-n-perfluoroalkylethyl)-2-oxazoline)s represent very hydrophobic PAOx. Interestingly, their melting temperatures are much higher compared to their hydrocarbon analogues and unlike them, the melting points increase as the side-chain length increases (Figure 2)..$^{98}$

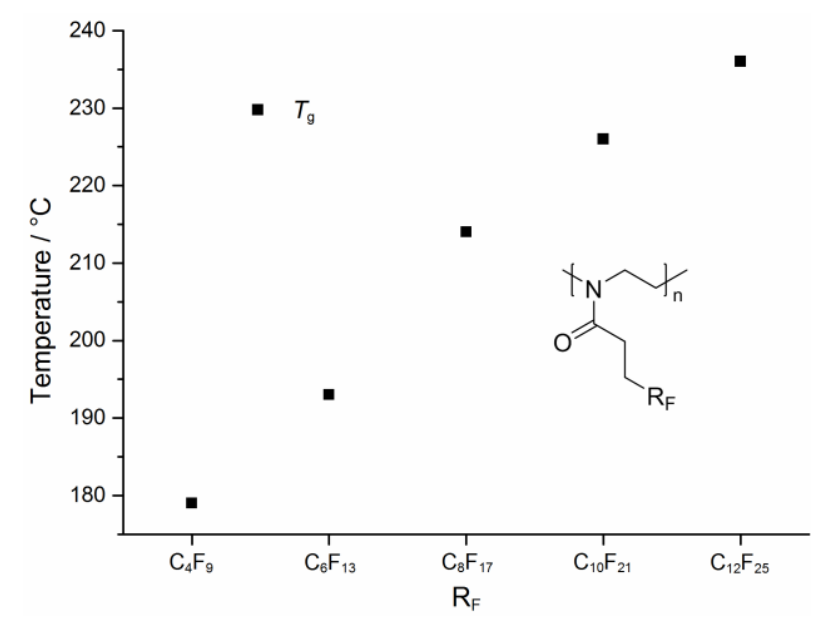


Figure 2. Glass transition temperatures of poly(2-n-perfluoroalkylethyl)-2-oxazoline)s obtained from DSC. Data are taken from ref. 98

The presence of the rigid aromatic phenyl ring in PPhOx leads to a higher $T_{\mathrm{g}}\left(103-107^{\circ} \mathrm{C}\right)^{3,19}$, ${ }^{87}$ compared to poly(2-n-alkyl-2-oxazoline)s such as PMeOx or PEtOx. Significantly higher $T_{\mathrm{g}}$ values were found for polymers with two ortho-fluoro substituents on the phenyl ring with the highest values for P2,4,6-TFOx $\left(T_{\mathrm{g}}=133^{\circ} \mathrm{C}\right)$ and P2,3,4,5,6-PFOx $\left(T_{\mathrm{g}}=135^{\circ} \mathrm{C}\right) .{ }^{123}$ All PAOx with functional groups in the side-chains whose thermal properties have been investigated were found to be amorphous and their glass transition temperatures are collected in table 8 .

\section{Mechanical properties of poly(2-oxazoline) homopolymers}

There are only very few reports on the mechanical properties of PAOx as the majority of polymers have a rather low molar mass leading to very poor (brittle) mechanical properties, thereby obstructing mechanical testing. The mechanical properties of low molar mass poly(2$n$-alkyl-2-oxazoline)s ( $D P=60$ ) have been reported based on nano-indentation on spin-coated polymer films. These measurements revealed that the mechanical properties are closely related to the thermal properties. Upon increasing the length of the alkyl side-chain from methyl to butyl, the elastic modulus decreases almost linearly ${ }^{89,151}$ (Figure 3) related to the decrease in $T_{\mathrm{g}}$ (Figure 3).

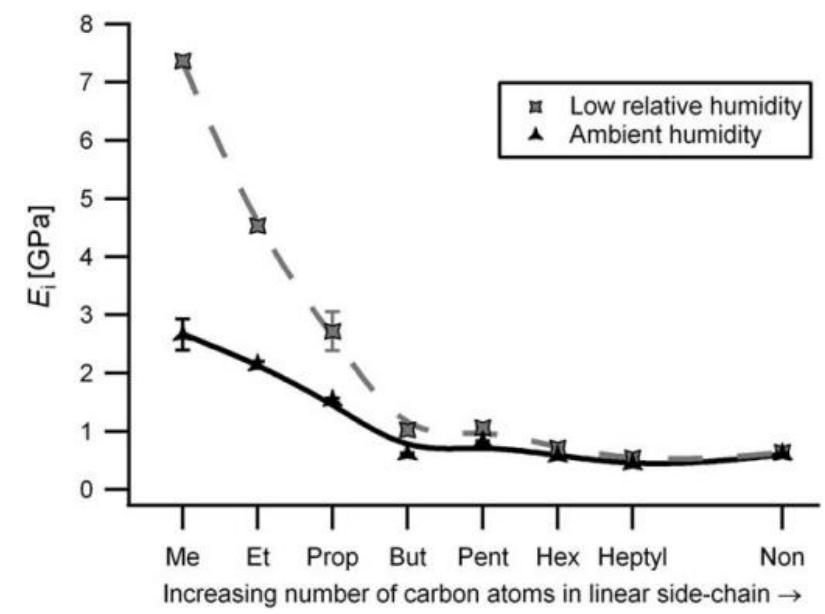


Figure 3. Indentation moduli of poly(2-n-alkyl-2-oxazoline)s with DP $\sim 60$ at low and ambient humidity. The lines are added to guide the eye only. Reproduced from Ref. 151 with permission from The Royal Society of Chemistry.

The polymers with more than 4 carbon atoms in the side-chain are semi-crystalline and have a $T_{\mathrm{g}}$ below ambient temperature and therefore the measurements were performed above their respective $T_{\mathrm{g}}$ resulting in moduli of ca. $0.8 \mathrm{GPa}$ which is common for polymers tested between their glass transition and melting temperatures. ${ }^{152}$ It should be noted that the mechanical properties of PMeOx, PEtOx and Pn-PrOx strongly depend on the humidity due to the hygroscopic nature of these polymers. As can be seen from Figure 3, the plasticizing effect of incorporated water reduces the indentation moduli. ${ }^{151}$ It is expected that more in depth mechanical properties of PAOx will become available in the near future based on the fact that well-defined high molar mass PAOx have become synthetically accessible recently.

\section{Surface properties of poly(2-oxazoline) homopolymers}

The surface properties of poly(2-n-alkyl-2-oxazoline)s are related to their thermal properties in a similar manner as their mechanical properties. Figure 4 shows the surface energies of poly(2-n-alkyl-2-oxazoline) thin films calculated from the surface angles using Neumann's equation of state. ${ }^{89}$

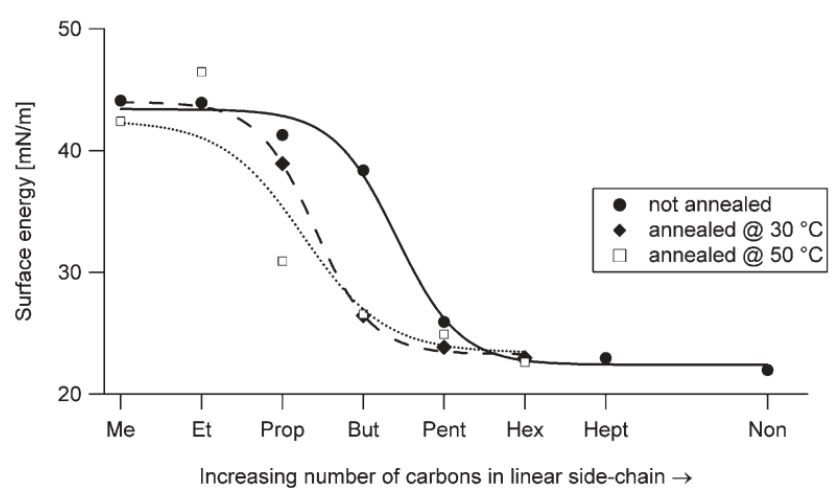

Figure 4. Surface energies of poly(2-n-alkyl-2-oxazoline)s with $M / I=100$. The lines are sigmoidal fits to the data points. Reproduced from Ref. 89 with permission from WILEY-VCH. 
Inspection of Figure 4 reveals a clear change in materials properties of the not annealed samples at $\mathrm{Pn}$-BuOx which has a $T_{\mathrm{g}}$ close to ambient temperature. The polymers with 5 or more carbon atoms in the side-chain were measured above their respective $T_{\mathrm{g}}$ and show low surface energies, due to segregation of the longer side-chains to the surface, which is favored by the higher flexibility of the polymer chains. PMeOx, PEtOx and Pn-PrOx were measured below their respective $T_{\mathrm{g}}$ and cannot orient the side-chains to the surfaces, resulting in higher surface energies. ${ }^{89}$ The surface energy of $\mathrm{P} n$-PrOx can be reduced by thermal annealing while no change was found for PMeOx and PEtOx even after annealing at $90{ }^{\circ} \mathrm{C}$ indicating that the methyl and ethyl side-chains are too short to fully cover the surface ${ }^{89} \mathrm{~A}$ similar surface energy as for poly(2-n-alkyl-2-oxazoline)s measured above their $T_{\mathrm{g}}$ was found for PPhOx $\left(42.6 \mathrm{mNm}^{-}\right.$ $\left.{ }^{1}\right) .{ }^{123}$ PAOx based on fluorophenyl oxazolines exhibited lower surface energies than PPhOx. ${ }^{123}$ However, the surface energy does not continuously decrease with increasing fluorine substitution. A detailed look at the effect of the substitution pattern on the surface energy (Figure 5) demonstrates the importance of especially the para-fluoro substituent in lowering the surface energy.

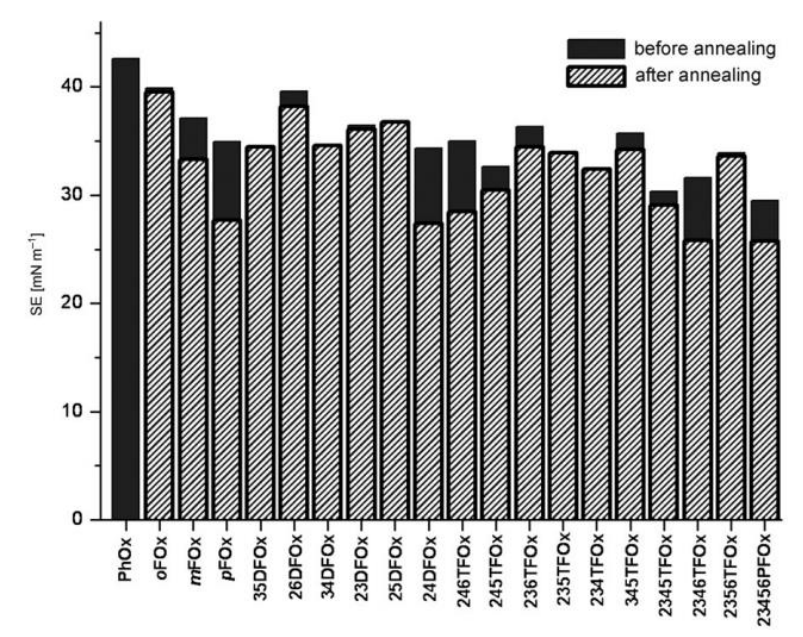

Figure 5. Surface energies (SEs) of the polymers of fluorophenyl oxazolines and PhOx before and after annealing $\left(16 \mathrm{~h}, 140^{\circ} \mathrm{C}\right)$. Reproduced from ref.123 with permission from WILEY-VCH. 
Rodriguez-Parada et al. ${ }^{98}$ investigated the behavior of PAOx with linear hydrocarbon and fluorocarbon side chains varying in length from 6 to 17 carbon atoms at the air-water interface in a Langmuir trough. Polymers with short hydrocarbon side chains (6-11 carbon atoms) were found to form fluid liquid like condensed monolayers in which the polymer backbone is at the water surface and the side chains are tilted toward the air. Polymers with longer side chains formed only rigid monolayers which tend to crystallize after the initial compression and Langmuir-Blodgett films of these materials could be prepared only with difficulty. Similar behavior was observed for polymers with fluorocarbon side chains, with the only difference that the same effects were observed at shorter side-chain lengths (usually 3 carbon atoms less), which can be explained by the higher hydrophobicity and rigidity of the fluorocarbon chains. ${ }^{98}$

\section{Solution properties of poly(2-oxazoline) homopolymers}

The variation of the side-chain structure of PAOx enables the tuning of the properties from very hydrophilic (PMeOx) to very hydrophobic (long alkyl or perfluoro alkyl side-chains) polymers. Consequently, the solution behavior of PAOx strongly depends on the side-chain structure. Table 9 gives an overview of the solubility of various PAOx with hydrocarbon sidechains in water and common organic solvents.

In addition to the solvents listed in Table 9, sulfolane was found to be a good solvent for high molar mass PMeOx. ${ }^{153}$ The semi-crystalline polymers $\mathrm{Pc}$-BuOx, $\mathrm{Pc}$-PentOx and $\mathrm{Pc}$-HexOx show poor solubility in many common organic solvents, but are soluble in 1,1,1,3,3,3-hexafluoro-2propanol (HFIP) and formic acid at ambient temperature that disrupt interchain interactions. ${ }^{117}$ The behavior of PAOx in aqueous solutions is influenced by the hydration of the polymer and the accompanied loss in entropy. With increasing temperature the entropy 
loss increases and at the phase transition temperature it becomes more favorable to release the water molecules into the bulk water resulting in agglomeration of the polymers chains (Figure 6). Therefore many PAOx exhibit a lower critical solution temperature (LCST). Two comprehensive reviews about thermoresponsive PAOx by Weber et al ${ }^{154}$ and Hoogenboom and Schlaad ${ }^{155}$ give an excellent overview on these polymers and their solution behavior.

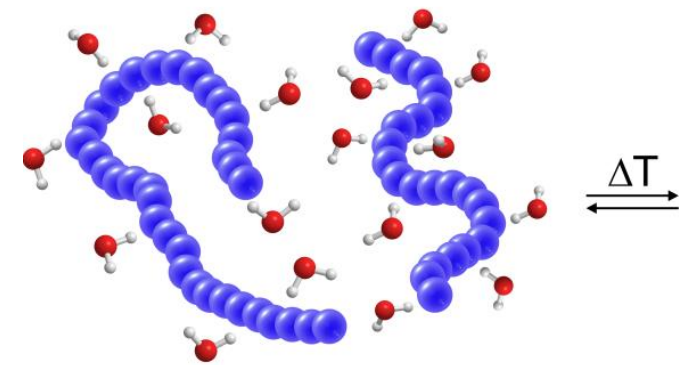

Hydrophilic coils

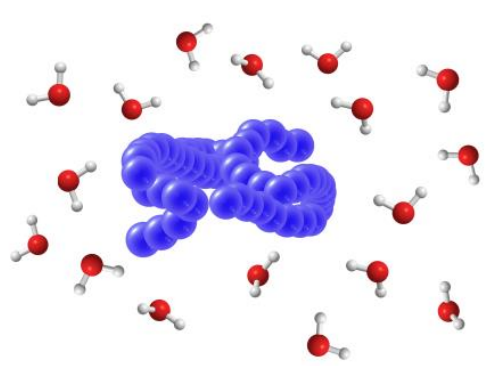

Hydrophobic globules

Figure 6. Schematic representation of a polymer phase transition in aqueous solution. Adapted from ref. 156 with permission from Elsevier.

While PMeOx, which has been claimed to be even more hydrophilic than PEG based on HPLC analysis $^{79}$ as well as based on the poor solubility of higher molar mass PMeOx in organic solvents like acetonitrile in which higher molar mass PEG is well soluble, ${ }^{153}$ is fully water soluble from $0-100{ }^{\circ} \mathrm{C}$, PAOx with longer alkyl side chains exhibit LCST behavior. Figure 7 shows the cloud point temperatures $\left(T_{\mathrm{CP}}\right.$, the temperature where the transmittance rapidly decreases due to agglomeration of the polymer chains) of PAOx with increasing hydrophobicity. It should be noted that the $T_{\mathrm{CP}}$ depends on the molar mass, the concentration, the polymer end-groups and the conditions of the measurement ${ }^{157}$ and therefore comparisons of $T_{\mathrm{CP}}$ 's reported in the literature should be handled with care. 


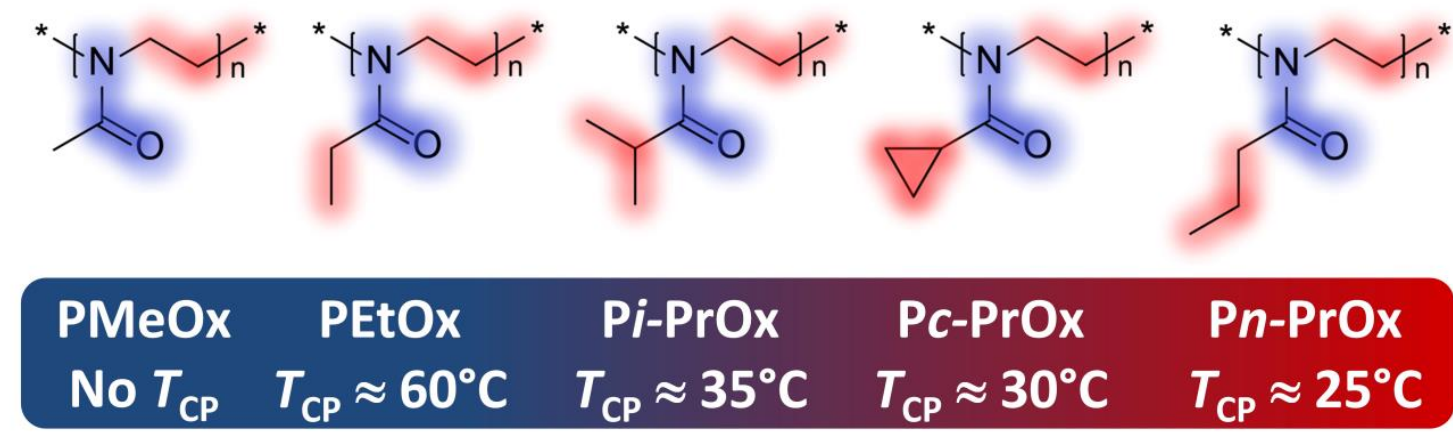

Figure 7. PAOx with hydrocarbon side-chains with increasing hydrophobicity (from left to right) and consequently decreasing cloud point temperature.

The LCST behavior of high molar mass PEtOx was first reported in 1988 by Lin et. al. with TCP's from 61-69 ${ }^{\circ} \mathrm{C}$ dependent on the concentration. ${ }^{91}$ Lowering the molar mass of PEtOx homopolymers results in a significant increase of the $T_{\mathrm{CP}}$ in aqueous solution. ${ }^{92,}{ }^{93}$ Amongst thermoresponsive polymers those with a LCST close to body temperature are of special interest for applications in drug delivery or bioengineering. ${ }^{158,} 159$ Interestingly, PAOx with propyl side-chains namely Pn-PrOx, Pc-PrOx and Pi-PrOx belong to this class of polymers. It was first reported in 1992 that Pi-PrOx exhibits LCST behavior with the $T_{\mathrm{CP}}$ decreasing from 39 to $35^{\circ} \mathrm{C}$ with increasing polymer concentration $(0.1-1 \mathrm{wt} \%) .{ }^{108}$ More detailed investigations of $\mathrm{Pi}$-PrOx with varying molar mass revealed that the $T_{\mathrm{CP}}$ decreases with increasing molar mass and that the concentration dependence becomes less pronounced with increasing molar mass. ${ }^{107,110,160}$ All of these studies found the phase transition to be reversible with a small heating-cooling hysteresis. However, it was later discovered that the transition becomes irreversible after keeping the dispersion longer above the cloud point due to isothermal crystallization of the (partially) dehydrated polymer chains. ${ }^{106,} 109$ It was recently shown that cyclic Pi-PrOx exhibits a much higher $T_{\mathrm{CP}}$ compared to linear Pi-PrOx with the same molar mass. ${ }^{161}$ As much as 15 years after the LCST behavior of Pi-PrOx was discovered, it was 
reported that Pn-PrOx also exhibits LCST behavior in aqueous solutions. ${ }^{95}$ The $T_{\mathrm{CP}}$ was found to be more than $10{ }^{\circ} \mathrm{C}$ lower compared to Pi-PrOx with a similar molar mass which is in accordance with the higher hydrophobicity. As previously observed for Pi-PrOx, the $T_{\mathrm{CP}}$ of PnPrOx also decreases with increasing molar mass. ${ }^{93}$ The cyclic side-chain structure of Pc-PrOx results in an intermediate hydrophobicity compared to Pi-PrOx and Pn-PrOx and consequently its $T_{\mathrm{CP}}$ in aqueous solution was found to be in between the $T_{\mathrm{CP}}$ 's observed for Pi-PrOx and PnPrOx. ${ }^{115,116}$ In contrast to Pi-PrOx the phase transitions of the amorphous Pn-PrOx and PcPrOx are fully reversible, even when kept above $T_{C P}$ for a prolonged time. PAOx with methyl ester side-chains were first reported $1968,{ }^{38}$ but it was only recently reported that these polymers exhibit thermoresponsive LCST behavior in aqueous solution. ${ }^{142}$ Their $T_{\mathrm{CP}}$ 's strongly depend on the length of the alkyl spacer. PC2MestOx shows a very similar solution behavior as PEtOx with a $T_{\mathrm{CP}}$ around $100^{\circ} \mathrm{C}$ for a polymer with DP 100 while PC3MestOx exhibits a $T_{\mathrm{CP}}$ around $25{ }^{\circ} \mathrm{C}$ similar to Pn-PrOx. In contrast to the LCST behavior, there are no poly(2oxazoline)s reported that show an upper critical solution temperature (UCST) in water. However, UCST behavior was observed for PAOx with phenyl, benzyl or alkyl side-chains longer than propyl in ethanol-water mixtures, ${ }^{112}$ which results from the change in polarity of these non-ideal solvent mixtures upon heating. ${ }^{162}$ Figure 8 shows an overview of the solubility of various PAOx in ethanol-water mixtures. 


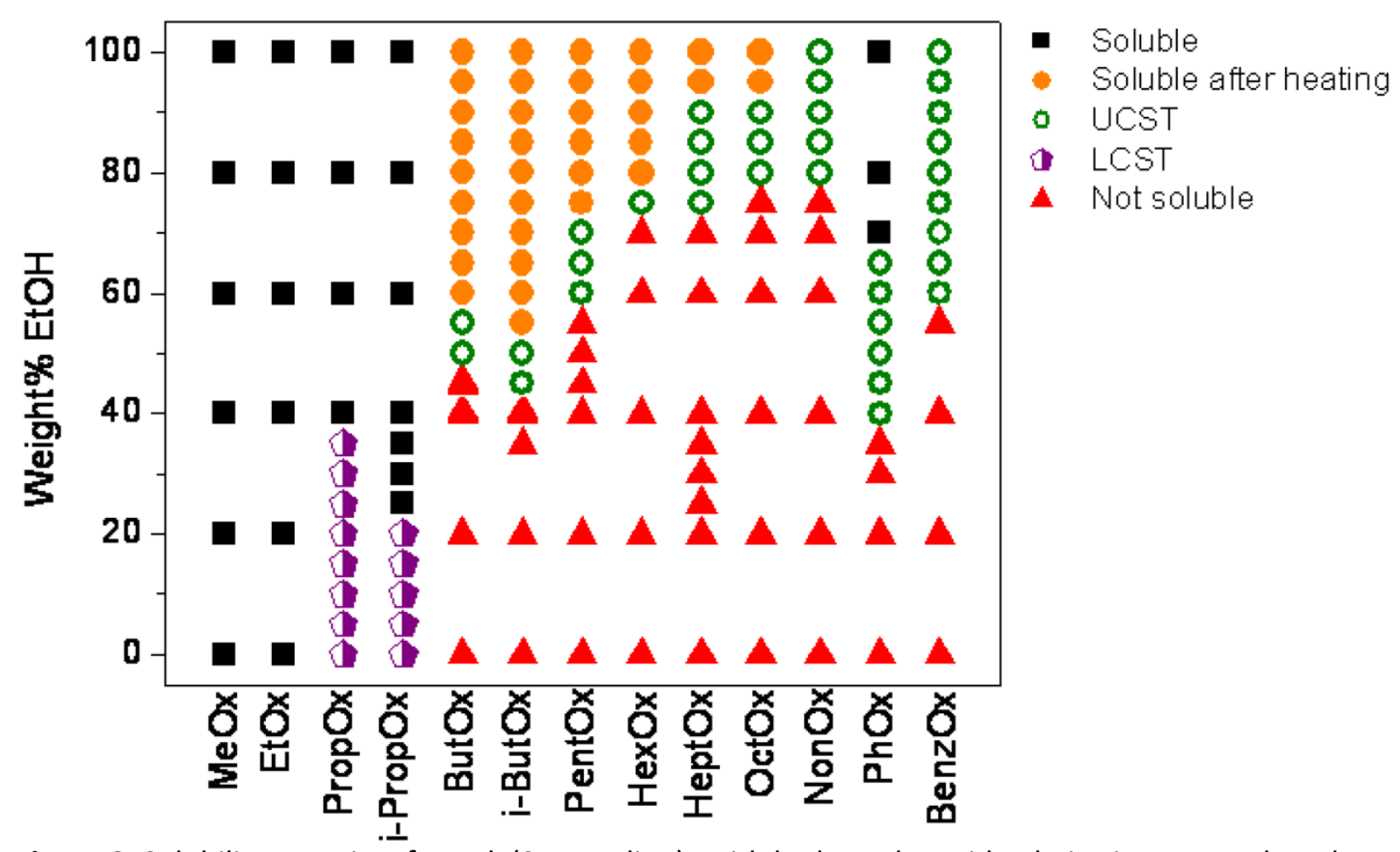

Figure 8. Solubility overview for poly(2-oxazoline)s with hydrocarbon side-chains in water-ethanol mixtures $(5 \mathrm{mg} / \mathrm{mL})$. Reproduced from ref. 112 with permission from MDPI AG.

\section{Conclusions and outlook}

In the last years PAOx have emerged as materials for biomedical and pharmaceutical applications, such as polymer-drug and polymer-protein conjugates, self-assembled carriers for drug delivery, solid dispersions, hydrogels, antibiofouling and antimicrobial surfaces, and wound healing. ${ }^{9,11-14,163}$ In the 50 years since the first reports on PAOx the CROP of more than one hundred different 2-oxazolines has been reported. In combination with the straightforward introduction of functional groups at the chain-ends, this allows the synthesis of a wide range of PAOx homo and copolymers with fine-tuned physical properties and chemical structures that can be further extended by post-polymerization modifications. The properties of PAOx range from amorphous polymers with glass transition temperatures well below ambient temperature to semi-crystalline polymers with melting points well above 200 ${ }^{\circ} \mathrm{C}$. Some PAOx are very hydrophilic water-soluble polymers while others are very 
hydrophobic. The toolbox for the construction of tailor-made PAOx that has been developed

in the last decades should enable researchers to develop exciting new applications especially, but not exclusively, in the biomedical field. We hope that this review will serve as a reference guide for the selection of 2-oxazoline monomers for the preparation of PAOx with the desired physical properties and/or chemical functionality, by providing a comprehensive overview of the different monomers and corresponding polymer properties.

\section{References}

Tomalia D A and Sheetz D P, J Polym Sci, Part A-1: Polym Chem 4:2253-2265 (1966).

Seeliger W, Aufderhaar E, Diepers W, Feinauer R, Nehring R, Thier W and Hellmann H, Angew Chem Int Ed 5:875-888 (1966).

Bassiri T G, Levy A and Litt M, J Polym Sci B: Polym Lett 5:871-879 (1967).

Kagiya T, Narisawa S, Maeda T and Fukui K, J Polym Sci B: Polym Lett 4:441-445 (1966). Do H-Q, Chandrashekar E R R and Fu G C, J Am Chem Soc 135:16288-16291 (2013). Nishiyama $\mathrm{H}$, Sakaguchi $\mathrm{H}$, Nakamura T, Horihata M, Kondo M and Itoh K, Organometallics 8:846-848 (1989).

Durini M, Russotto E, Pignataro L, Reiser O and Piarulli U, Eur J Org Chem 2012:5451-5461 (2012).

Adams N and Schubert U S, Adv Drug Delivery Rev 59:1504-1520 (2007). de la Rosa V R, J Mater Sci - Mater Med 25:1211-1225 (2014).

Hoogenboom R, Angew Chem Int Ed 48:7978-7994 (2009).

Luxenhofer R, Han Y, Schulz A, Tong J, He Z, Kabanov A V and Jordan R, Macromol Rapid Commun 33:1613-1631 (2012).

Sedlacek O, Monnery B D, Filippov S K, Hoogenboom R and Hruby M, Macromol Rapid Commun 33:1648-1662 (2012).

Vlassi E, Papagiannopoulos A and Pispas S, Eur Polym J 88:516-523 (2017).

Wilson P, Ke P C, Davis T P and Kempe K, Eur Polym J 88:486-515 (2017). Luxenhofer R, Huber S, Hytry J, Tong J, Kabanov A V and Jordan R, J Polym Sci, Part A: Polym Chem 51:732-738 (2013).

Lambermont-Thijs H M L, Fijten M W M, van der Linden A J, van Lankvelt B M, Bloksma M M, Schubert U S and Hoogenboom R, Macromolecules 44:4320-4325 (2011).

Bloksma M M, Schubert U S and Hoogenboom R, Macromol Rapid Commun 32:1419-1441 (2011).

Saegusa T, Hirao T and Ito Y, Macromolecules 8:87-87 (1975).

Beck M, Birnbrich P, Eicken U, Fischer H, Fristad W E, Hase B and Krause H J, Angew Makromol Chem 223:217-233 (1994).

Kempe K, Lobert M, Hoogenboom R and Schubert U S, J Comb Chem 11:274-280 (2009).

Witte H and Seeliger W, Justus Liebigs Ann Chem 1974:996-1009 (1974).

Wenker H, J Am Chem Soc 57:1079-1080 (1935).

Taubmann C, Luxenhofer R, Cesana S and Jordan R, Macromol Biosci 5:603-612 (2005). 
Dargaville T R, Lava K, Verbraeken B and Hoogenboom R, Macromolecules 49:4774-4783 (2016).

25 Verbraeken B, Lava K and Hoogenboom R, Poly(2-oxazoline)s, in Encyclopedia of Polymer Science and Technology. John Wiley \& Sons, Inc. (2002).

Glassner M, D'hooge D R, Young Park J, Van Steenberge P H M, Monnery B D, Reyniers M-F and Hoogenboom R, Eur Polym J 65:298-304 (2015).

Fijten M W M, Hoogenboom R and Schubert U S, J Polym Sci, Part A: Polym Chem 46:48044816 (2008).

Hoogenboom R, Fijten M W M and Schubert U S, J Polym Sci, Part A: Polym Chem 42:18301840 (2004).

Einzmann M and Binder W H, J Polym Sci, Part A: Polym Chem 39:2821-2831 (2001).

Kourti M-E, Vougioukalakis G C, Hadjichristidis N and Pitsikalis M, J Polym Sci, Part A: Polym Chem 49:2520-2527 (2011). (2008).

Guillerm B, Monge S, Lapinte V and Robin J-J, Macromol Rapid Commun 33:1600-1612 (2012). Levy A and Litt M, J Polym Sci, Part A-1: Polym Chem 6:63-72 (1968). Levy A and Litt M, J Polym Sci, Part A-1: Polym Chem 6:1883-1894 (1968). Baumgaertel A, Weber C, Knop K, Crecelius A and Schubert U S, Rapid Commun Mass Spectrom 23:756-762 (2009).

Monnery B D, Shaunak S, Thanou M and Steinke J H G, Macromolecules 48:3197-3206 (2015). Verbraeken B, Monnery B D, Lava K and Hoogenboom R, Eur Polym J 88:451-469 (2017). Hoogenboom R and Monnery B, Method for the preparation of uniform, high molar mass cyclic imino ether polymers. WO2016008817 A1 (2016).

Nuyken O, Maier G, Groß A and Fischer H, Macromol Chem Phys 197:83-95 (1996). Kobayashi S, Masuda E, Shoda S and Shimano Y, Macromolecules 22:2878-2884 (1989). Park J-S and Kataoka K, Macromolecules 39:6622-6630 (2006). de la Rosa V R, Tempelaar S, Dubois P, Hoogenboom R and Mespouille L, Polym Chem 7:1559-1568 (2016).

Christova D, Velichkova R and Goethals E J, Macromol Rapid Commun 18:1067-1073 (1997). Miyamoto M, Naka K, Tokumizu M and Saegusa T, Macromolecules 22:1604-1607 (1989). Weber C, Krieg A, Paulus R M, Lambermont-Thijs H M L, Becer C R, Hoogenboom R and Schubert U S, Macromol Symp 308:17-24 (2011).

David G, Alupei V and Simionescu B C, Eur Polym J 37:1353-1358 (2001). David G and loanid A, J Appl Polym Sci 80:2191-2199 (2001). Shimano Y, Sato K and Kobayashi S, J Polym Sci, Part A: Polym Chem 33:2715-2723 (1995). Chujo Y, Ihara E, Ihara H and Saegusa T, Macromolecules 22:2040-2043 (1989). Förtig A, Jordan R, Graf K, Schiavon G, Purrucker O and Tanaka M, Macromol Symp 210:329338 (2004).

Kobayashi S, Kaku M, Sawada S and Saegusa T, Polym Bull 13:447-451 (1985). Volet G, Deschamps A-C L and Amiel C, J Polym Sci, Part A: Polym Chem 48:2477-2485 (2010). Chujo $Y$, Ihara E, Kure $S$ and Saegusa T, Macromolecules 26:5681-5686 (1993). Stadermann J, Komber H, Erber M, Däbritz F, Ritter H and Voit B, Macromolecules 44:32503259 (2011).

Adeli M, Kalantari M, Zarnega Z and Kabiri R, RSC Advances 2:2756-2758 (2012). Jordan R, West N, Ulman A, Chou Y M and Nuyken O, Macromolecules 34:1606-1611 (2001). 

24:92-97 (2003).

62 Schmitz M, Kuhlmann M, Reimann O, Hackenberger C P R and Groll J, Biomacromolecules 16:1088-1094 (2015).

63 Van Caeter P, Goethals E J, Gancheva V and Velichkova R, Polym Bull 39:589-596 (1997).

64 Tong J, Luxenhofer R, Yi X, Jordan R and Kabanov A V, Mol Pharm 7:984-992 (2010).

65 Glassner M, Palmieri L, Monnery B D, Verbrugghen T, Deleye S, Stroobants S, Staelens S, wyffels L and Hoogenboom R, Biomacromolecules 18:96-102 (2017). Luxenhofer R and Jordan R, Macromolecules 39:3509-3516 (2006). Isaacman M J, Corigliano E M and Theogarajan L S, Biomacromolecules 14:2996-3000 (2013). Rueda J C, Komber H, Cedrón J C, Voit B and Shevtsova G, Macromol Chem Phys 204:947-953 (2003). Waschinski C J and Tiller J C, Biomacromolecules 6:235-243 (2005).

Waschinski C J, Herdes V, Schueler F and Tiller J C, Macromol Biosci 5:149-156 (2005). Cirpan A, Alkan S, Toppare L, David G and Yagci Y, Eur Polym J 37:22225-2229 (2001). Nawroth J F, McDaniel J R, Chilkoti A, Jordan R and Luxenhofer R, Macromol Biosci 16:322333 (2016).

73 Tauhardt L, Frant M, Pretzel D, Hartlieb M, Bucher C, Hildebrand G, Schroter B, Weber C, Kempe K, Gottschaldt M, Liefeith K and Schubert U S, J Mater Chem B 2:4883-4893 (2014). Volet G, Lav T-X, Babinot J and Amiel C, Macromol Chem Phys 212:118-124 (2011). Lemechko P, Renard E, Volet G, Colin C S, Guezennec J and Langlois V, React Funct Polym 72:160-167 (2012).

76 Rudolph T, Kumar Allampally N, Fernández G and Schacher F H, Chem Eur J 20:13871-13875 (2014).

Osawa S, Ishii T, Takemoto H, Osada K and Kataoka K, Eur Polym J 88:553-561 (2017). Loontjens T and Rique-Lurbet L, Des Monomers Polym 2:217-229 (1999).

Viegas T X, Bentley M D, Harris J M, Fang Z, Yoon K, Dizman B, Weimer R, Mero A, Pasut G and Veronese F M, Bioconjugate Chem 22:976-986 (2011). Moreadith R W, Viegas T X, Bentley M D, Harris J M, Fang Z, Yoon K, Dizman B, Weimer R, Rae B P, Li X, Rader C, Standaert D and Olanow W, Eur Polym J 88:524-552 (2017). de la Rosa V R, Zhang Z, De Geest B G and Hoogenboom R, Adv Funct Mater 25:2511-2519 (2015).

82 Glassner M, Kempe K, Schubert U S, Hoogenboom R and Barner-Kowollik C, Chem Commun 47:10620-10622 (2011).

83 Hoogenboom R, Fijten M W M, Thijs H M L, van Lankvelt B M and Schubert U S, Des Monomers Polym 8:659-671 (2005).

84 Goossens H, Catak S, Glassner M, de la Rosa V R, Monnery B D, De Proft F, Van Speybroeck V and Hoogenboom R, ACS Macro Lett 2:651-654 (2013).

85 Kobayashi S, Tokuzawa T and Saegusa T, Macromolecules 15:707-710 (1982). Lobert M, Kohn U, Hoogenboom R and Schubert U S, Chem Commun 1458-1460 (2008). Wiesbrock F, Hoogenboom R, Leenen M, van Nispen S F G M, van der Loop M, Abeln C H, van den Berg A M J and Schubert U S, Macromolecules 38:7957-7966 (2005). Kranenburg J M, Tweedie C A, Hoogenboom R, Wiesbrock F, Thijs H M L, Hendriks C E, Van Vliet K J and Schubert U S, J Mater Chem 17:2713-2721 (2007). Rettler E F J, Kranenburg J M, Lambermont-Thijs H M L, Hoogenboom R and Schubert U S, Macromol Chem Phys 211:2443-2448 (2010).

$90 \quad$ Keskkula H and Paul D R, J Appl Polym Sci 31:941-950 (1986).

91 Lin P, Clash C, Pearce E M, Kwei T K and Aponte M A, J Polym Sci, Part B: Polym Phys 26:603619 (1988).

92 Christova D, Velichkova R, Loos W, Goethals E J and Prez F D, Polymer 44:2255-2261 (2003).

93 Hoogenboom R, Thijs H M L, Jochems M J H C, van Lankvelt B M, Fijten M W M and Schubert U S, Chem Commun 5758-5760 (2008). 
94 Kobayashi S, Kaku M and Saegusa T, Macromolecules 21:334-338 (1988).

95 Park J-S and Kataoka K, Macromolecules 40:3599-3609 (2007).

96 Huber S and Jordan R, Colloid Polym Sci 286:395-402 (2008).

97 Salzinger S, Huber S, Jaksch S, Busch P, Jordan R and Papadakis C M, Colloid Polym Sci 290:385-400 (2012).

98 Rodriguez-Parada J M, Kaku M and Sogah D Y, Macromolecules 27:1571-1577 (1994).

99 Kempe K, Lobert M, Hoogenboom R and Schubert U S, J Polym Sci, Part A: Polym Chem 47:3829-3838 (2009).

100 Cai G, Litt M H and Krieger I M, J Polym Sci, Part B: Polym Phys 29:773-784 (1991).

101 Gress A, Völkel A and Schlaad H, Macromolecules 40:7928-7933 (2007).

102 Kempe K, Hoogenboom R and Schubert U S, Macromol Rapid Commun 32:1484-1489 (2011).

103 Hoogenboom R, Thijs H M L, Fijten M W M and Schubert U S, J Polym Sci, Part A: Polym Chem 45:5371-5379 (2007).

104 Hoogenboom R and Schubert U S, Green Chemistry 8:895-899 (2006).

105 Binder W H and Gruber H, Macromol Chem Phys 201:949-957 (2000).

106 Demirel A L, Meyer M and Schlaad H, Angew Chem Int Ed 46:8622-8624 (2007).

107 Diab C, Akiyama Y, Kataoka K and Winnik F M, Macromolecules 37:2556-2562 (2004).

108 Uyama H and Kobayashi S, Chem Lett 21:1643-1646 (1992).

109 Meyer M, Antonietti M and Schlaad H, Soft Matter 3:430-431 (2007).

110 Zhao J, Hoogenboom R, Van Assche G and Van Mele B, Macromolecules 43:6853-6860 (2010).

111 Diehl C, Dambowsky I, Hoogenboom R and Schlaad H, Macromol Rapid Commun 32:17531758 (2011).

112 Lambermont-Thijs H M L, Kuringen H P C v, Put J P W v d, Schubert U S and Hoogenboom R, Polymers 2:188 (2010).

113 Kempe K, Rettler E F J, Paulus R M, Kuse A, Hoogenboom R and Schubert U S, Polymer 54:2036-2042 (2013).

114 Kempe K, Jacobs S, Lambermont-Thijs H M L, Fijten M M W M, Hoogenboom R and Schubert U S, Macromolecules 43:4098-4104 (2010).

115 Bloksma M M, Weber C, Perevyazko I Y, Kuse A, Baumgärtel A, Vollrath A, Hoogenboom R and Schubert U S, Macromolecules 44:4057-4064 (2011).

116 Glassner M, Lava K, de la Rosa V R and Hoogenboom R, J Polym Sci, Part A: Polym Chem 52:3118-3122 (2014).

117 Jerca V V, Lava K, Verbraeken B and Hoogenboom R, Polym Chem 7:1309-1322 (2016).

118 Hsieh B R and Litt M H, J Polym Sci, Part A: Polym Chem 26:2501-2515 (1988).

119 Hoogenboom R, Thijs H M L, Fijten M W M, van Lankvelt B M and Schubert U S, J Polym Sci, Part A: Polym Chem 45:416-422 (2007).

120 Hoogenboom R, Fijten M W M and Schubert U S, Macromol Rapid Commun 25:339-343 (2004).

121 Miyamoto M, Hayashizaki K, Tokumizu M and Saegusa T, Macromolecules 23:4718-4720 (1990).

122 Culbertson B M and Tong Y, Macromol Symp 156:253-262 (2000).

123 Lobert M, Thijs H M L, Erdmenger T, Eckardt R, Ulbricht C, Hoogenboom R and Schubert U S, Chem Eur J 14:10396-10407 (2008).

124 Percec V, Holerca M N, Magonov S N, Yeardley D J P, Ungar G, Duan H and Hudson S D, Biomacromolecules 2:706-728 (2001).

125 Stebani U and Lattermann G, J Macromol Sci, Pure Appl Chem 32:385-401 (1995).

126 Mrozek R A, Kim B-S, Holmberg V C and Taton T A, Nano Lett 3:1665-1669 (2003).

127 Cesana S, Auernheimer J, Jordan R, Kessler H and Nuyken O, Macromol Chem Phys 207:183192 (2006).

128 Miyamoto M, Shimakura M, Tsutsui K, Hasegawa K, Aoi K, Yamaga S and Saegusa T, Macromolecules 26:7116-7124 (1993). 

(1991).

130 Hermes R E, Thompson R D and Valdez L S, Polym Prepr (Am Chem Soc, Div Polym Chem) 36:219-220 (1995).

131 Cortez M A and Grayson S M, Macromolecules 43:4081-4090 (2010).

132 Hartlieb M, Pretzel D, Kempe K, Fritzsche C, Paulus R M, Gottschaldt M and Schubert U S, Soft Matter 9:4693-4704 (2013).

133 Simionescu C I, Rabia I and Harfas I, Polym Bull 7:129-135 (1982).

134 Hsieh B R and Litt M H, Macromolecules 19:516-520 (1986).

135 Lüdtke K, Jordan R, Hommes P, Nuyken O and Naumann C A, Macromol Biosci 5:384-393 (2005).

136 Dandreaux G, Login R B, Merianos J J, Garelick P, Plochocka K, Negrin M and Shih J S, Poly(pyrrolidonyl oxazoline). US5008367 A (1991).

137 Le Fer G, Amiel C and Volet G, Eur Polym J 71:523-533 (2015).

138 Lav T-X, Lemechko P, Renard E, Amiel C, Langlois V and Volet G, React Funct Polym 73:10011008 (2013).

139 Cai G and Litt M H, J Polym Sci, Part A: Polym Chem 30:649-657 (1992).

140 Cai G and Litt M H, J Polym Sci, Part A: Polym Chem 30:659-669 (1992).

141 Bouten P J M, Hertsen D, Vergaelen M, Monnery B D, Boerman M A, Goossens H, Catak S, van Hest J C M, Van Speybroeck V and Hoogenboom R, Polym Chem 6:514-518 (2015).

142 Bouten P, Lava K, van Hest J and Hoogenboom R, Polymers 7:1494 (2015).

143 Bouten P J M, Hertsen D, Vergaelen M, Monnery B D, Catak S, van Hest J C M, Van Speybroeck V and Hoogenboom R, J Polym Sci, Part A: Polym Chem 53:2649-2661 (2015).

144 Persigehl P, Jordan R and Nuyken O, Macromolecules 33:6977-6981 (2000).

145 Cesana S, Kurek A, Baur M A, Auernheimer J and Nuyken O, Macromol Rapid Commun 28:608-615 (2007).

146 Takasu A and Kojima H, J Polym Sci, Part A: Polym Chem 48:5953-5960 (2010).

147 Miyamoto M, Aoi K and Saegusa T, Macromolecules 21:1880-1883 (1988).

148 Miyamoto M, Aoi K and Saegusa T, Macromolecules 24:11-16 (1991).

149 Sogah D Y, Kaku M, Shinohara K-i, Rodriguez-Parada J M and Levy M, Makromol Chem, Macromol Symp 64:49-64 (1992).

150 Demirel A L, Tatar Güner P, Verbraeken B, Schlaad H, Schubert U S and Hoogenboom R, J Polym Sci, Part B: Polym Phys 54:721-729 (2016).

151 Rettler E F J, Lambermont-Thijs H M L, Kranenburg J M, Hoogenboom R, Unger M V, Siesler H W and Schubert U S, J Mater Chem 21:17331-17337 (2011).

152 Young R J and Lovell P A, Introduction to Polymers, Third Edition, Taylor \& Francis (2011).

153 Vergaelen M, Verbraeken B, Monnery B D and Hoogenboom R, ACS Macro Lett 4:825-828 (2015).

154 Weber C, Hoogenboom R and Schubert U S, Prog Polym Sci 37:686-714 (2012).

155 Hoogenboom R and Schlaad H, Polym Chem 8:24-40 (2017).

156 Vancoillie G, Frank D and Hoogenboom R, Prog Polym Sci 39:1074-1095 (2014).

157 Zhang Q, Weber C, Schubert U S and Hoogenboom R, Materials Horizons 4:109-116 (2017).

158 Schmaljohann D, Adv Drug Delivery Rev 58:1655-1670 (2006).

159 Ward M A and Georgiou T K, Polymers 3:1215-1242 (2011).

160 Park J-S, Akiyama Y, Winnik F M and Kataoka K, Macromolecules 37:6786-6792 (2004).

161 Jung Y, Kim J-H and Jang W-D, Eur Polym J 88:605-612 (2017).

162 Zhang Q and Hoogenboom R, Prog Polym Sci 48:122-142 (2015).

163 Morgese G and Benetti E M, Eur Polym J 88:470-485 (2017). 
Table 1 Terminating agents for the CROP of 2-oxazolines and structures of the resulting endfunctionalized PAOx. The $\alpha$-chain-end is shown as methyl group for reasons of brevity.

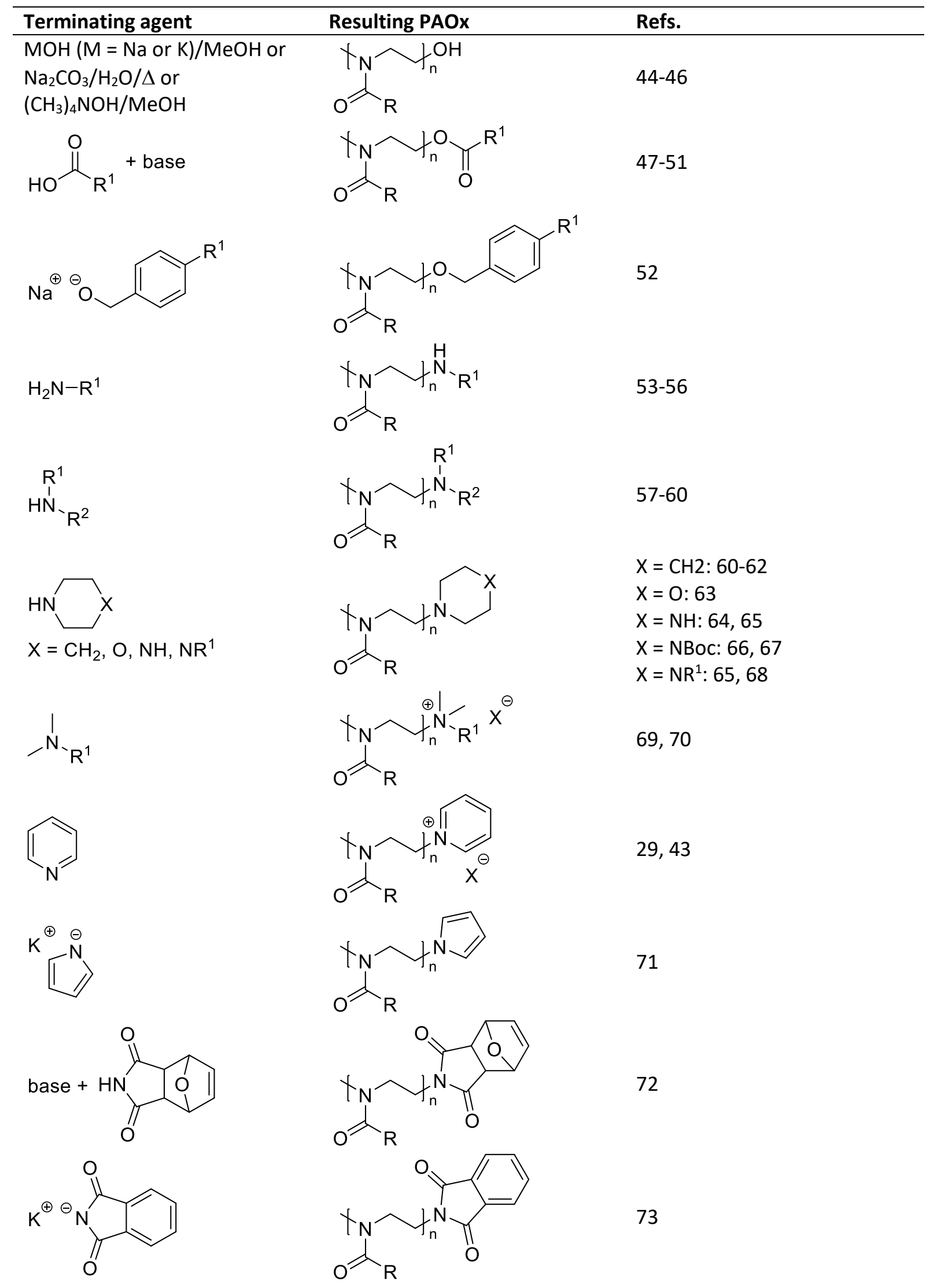


$\mathrm{NaN}_{3}$

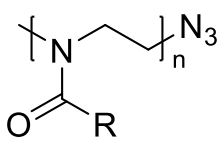

$\mathrm{R}^{1} \mathrm{~S}^{\ominus} \mathrm{M}^{\oplus}$

( $\mathrm{M}=\mathrm{Na}$ or $\mathrm{K}$ )

$\mathrm{K}^{\oplus}{ }^{\ominus} \mathrm{S} \prod_{\mathrm{S}} \mathrm{O} \longrightarrow$

@ $\mathrm{Na}^{\oplus}$
$t_{N} \sim \gamma_{n}^{S} R^{1}$

$\lambda_{R}$

$\gamma_{\mathrm{N}}^{\gamma_{\mathrm{S}}} \prod_{\mathrm{S}}^{\mathrm{O}}$<smiles>CNCCCC1=CC=CC1</smiles>

$\gamma_{R}$
$78-80$

52,81

82

Table 2 2-Oxazolines with linear alkyl substituents without heteroatoms. References refer to the preparation and properties of the respective homopolymers. For DiyneOx only copolymerization has been reported.

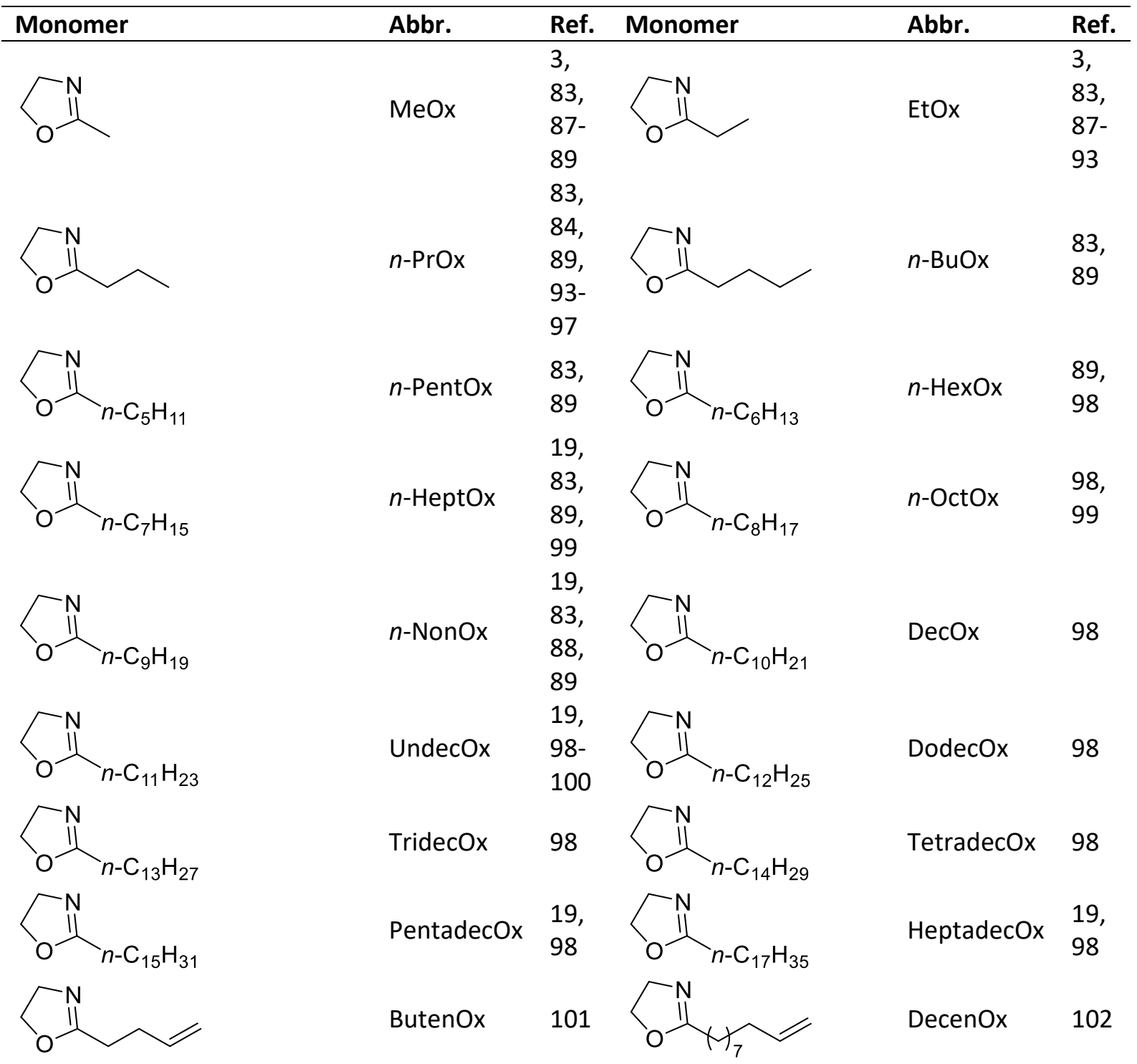




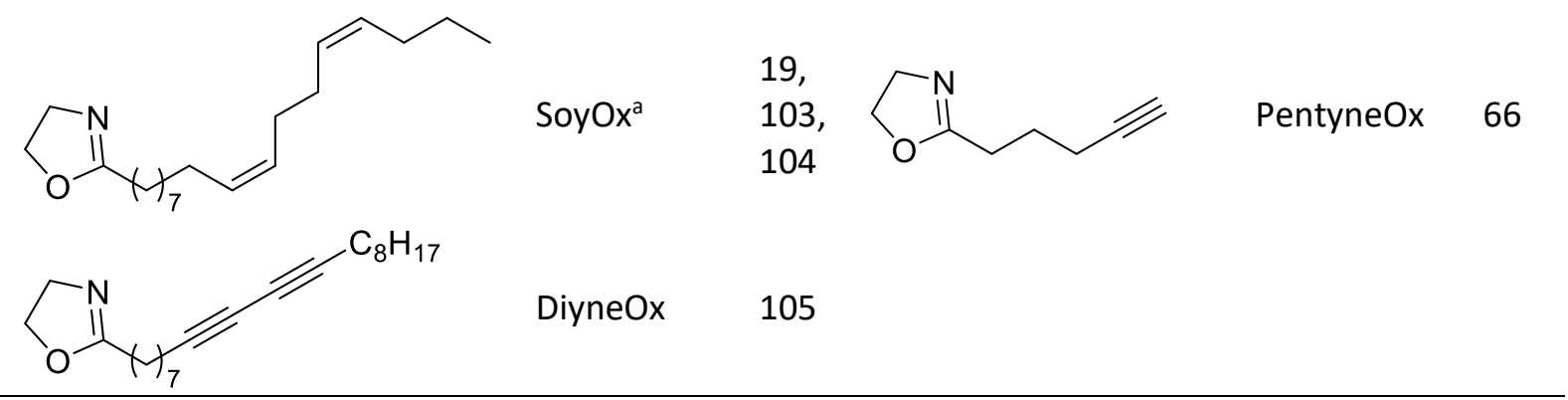

aSoyOx is based on soy-bean fatty acids and has on average 17 carbon atoms and 1.5 double bonds per monomer unit. 
Table 3 2-Oxazolines with branched or cyclic alkyl substituents without heteroatoms. References refer to the preparation and properties of the respective homopolymers.

\begin{tabular}{|c|c|c|c|c|c|}
\hline Monomer & Abbr. & Ref. & Monomer & Abbr. & Ref. \\
\hline & $i$-PrOx & $\begin{array}{l}45,84, \\
95,106- \\
110\end{array}$ & & $i$-BuOx & $\begin{array}{l}99,111, \\
112\end{array}$ \\
\hline & EPOx & 113 & & $3 E P O x$ & 113 \\
\hline & EHOx & 114 & & $c-\mathrm{PrOx}$ & $\begin{array}{l}84,115, \\
116\end{array}$ \\
\hline & $c$-BuOx & 117 & & c-PentOx & 117 \\
\hline & $c-\mathrm{HexOx}$ & 117 & & AdamOx & 118 \\
\hline & MeAdamOx & 118 & & & \\
\hline
\end{tabular}


Table 4 2-Oxazolines with phenyl or benzyl substituents. References refer to the preparation and properties of the respective homopolymers. For $p-\mathrm{N}_{3} \mathrm{PhOx}$ and CinamPhOx only copolymerizations have been reported. 


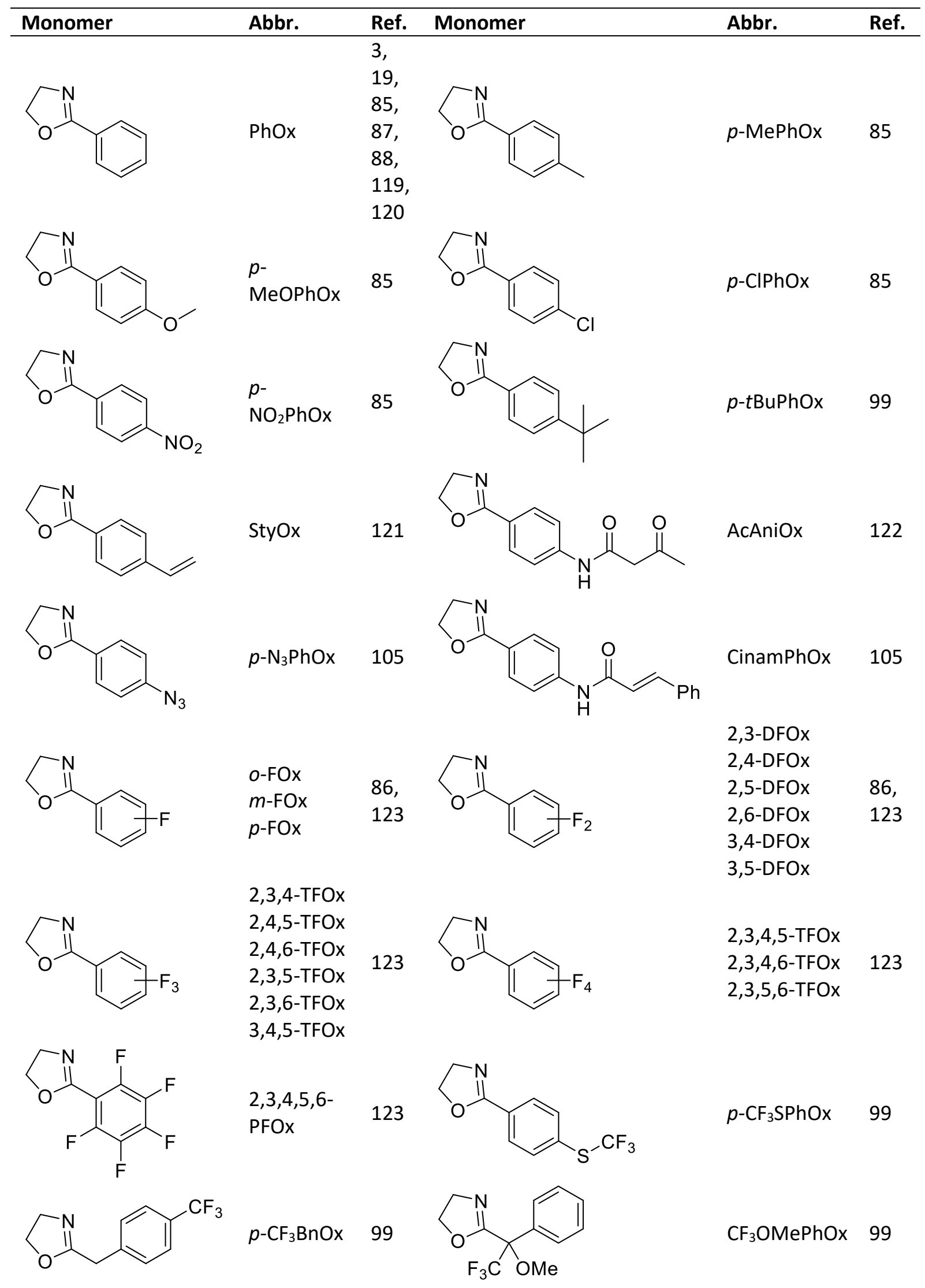




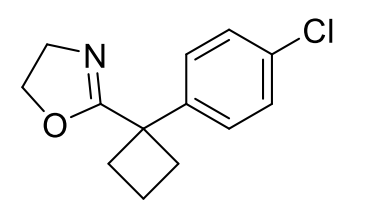

c-Bup-
CIPhOx

99

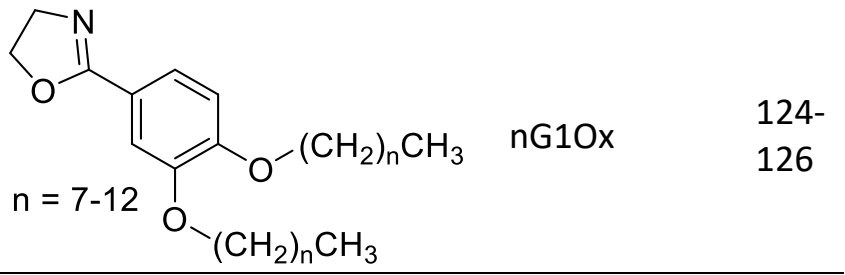

Table 5 2-Oxazolines with a nitrogen or phosphorous heteroatom in the substituent. References refer to the preparation and properties of the respective homopolymers.

Aber.


Table 6 2-Oxazolines with oxygen or sulfur heteroatoms in the substituent. References refer to the preparation and properties of the respective homopolymers. For HeptArIOx and MobsOx only copolymerizations have been reported.

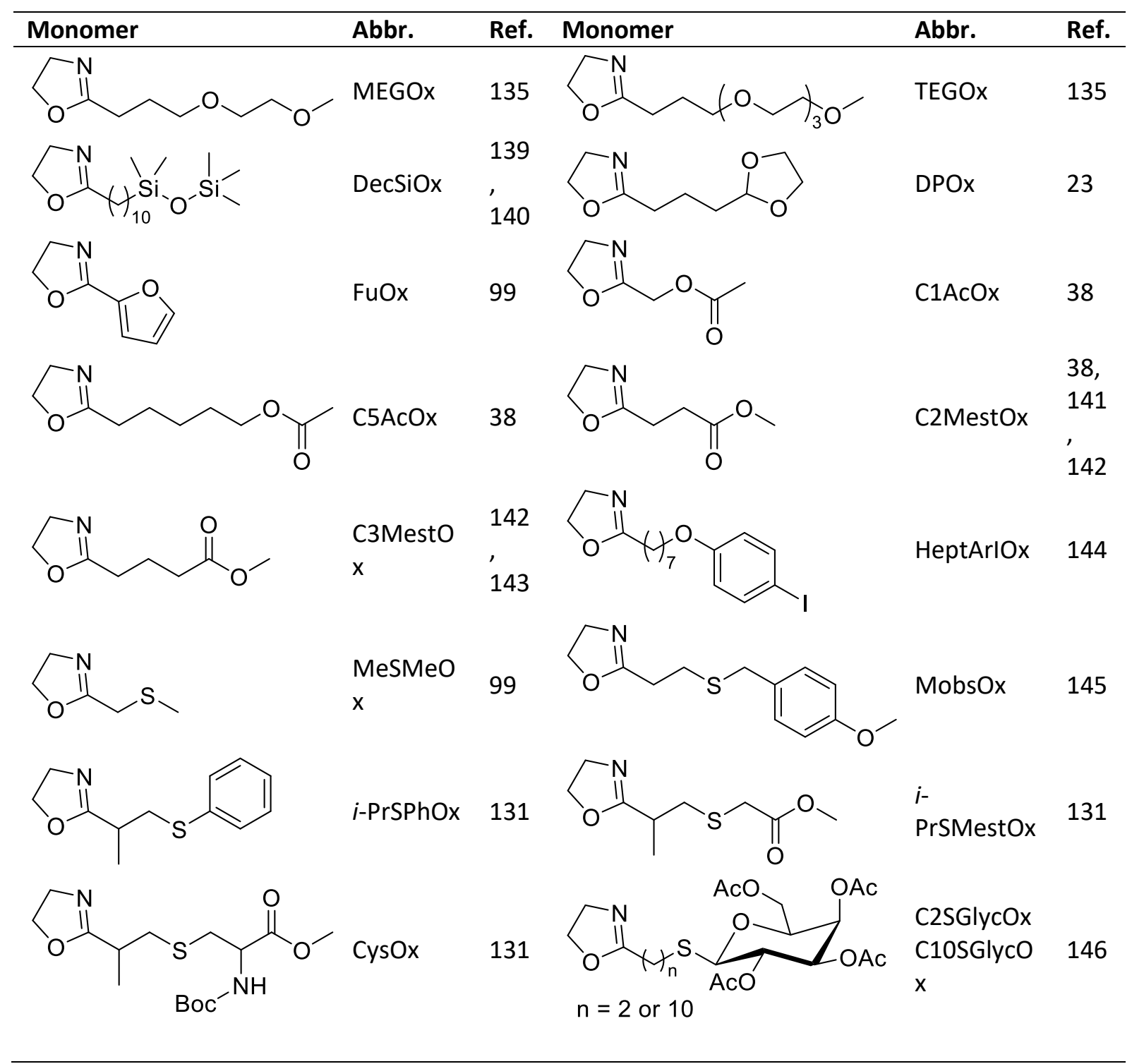

Table 7 2-Oxazolines with a perfluoroalkyl substituent. References refer to the preparation and properties of the respective homopolymers. 


\begin{tabular}{|c|c|c|c|c|c|}
\hline Monomer & Abbr. & Ref. & Monomer & Abbr. & Ref. \\
\hline & $\mathrm{C} 2 \mathrm{~F} 50 \mathrm{x}$ & $\begin{array}{l}147, \\
148\end{array}$ & & C3F70x & $\begin{array}{l}147 \\
148\end{array}$ \\
\hline & C7F15Ox & 148 & $\mathrm{n}=3,5$ & $\mathrm{C} 2 \mathrm{CnF}(2 \mathrm{n}+1) \mathrm{Ox}$ & $\begin{array}{l}98, \\
149\end{array}$ \\
\hline
\end{tabular}

Table 8. Glass transition temperatures of miscellaneous PAOx homopolymers

\begin{tabular}{lll}
\hline Polymer & $\boldsymbol{T}_{\mathrm{g}} /{ }^{\circ} \mathrm{C}$ & Ref. \\
\hline PButenOx & 17 & 101 \\
PAcAniOx & 35 & 122 \\
Pp-CF SPhOx $_{3}$ & 100 & 99 \\
Pp-CF 3 BnOx & 75 & 99 \\
PCF $_{3}$ OMePhOx & 89 & 99 \\
Pc-Bu- $p$-CIPhOx & 112 & 99 \\
PC4NHBocOx & 47 & 132 \\
PC2CarbOx & 130 & 134 \\
PC4CarbOx & 99 & 134 \\
PC2MestOx & 39 & 142 \\
PC3MestOx & -1 & 142 \\
PMeSMeOx & 39 & 99 \\
\hline
\end{tabular}

Table 9. Solubility of PAOx with hydrocarbon side-chains in water and various organic solvents. $\mathrm{MeOH}$ $=$ methanol, $\mathrm{CHCl}_{3}=$ chloroform, $\mathrm{MeCN}=$ acetonitrile, $\mathrm{DMF}=\mathrm{N}, \mathrm{N}^{\prime}$-Dimethylformamide, $\mathrm{PhCl}=$ Chlorobenzene, DMAc $=N, N^{\prime}-$ Dimethylacetamide.$+=$ soluble,$-=$ insoluble,$+/-=$ partially soluble, LCST $=$ lower critical solution temperature

\begin{tabular}{lccccccc}
\hline & Water & $\mathrm{MeOH}$ & $\mathrm{CHCl}_{3}$ & $\mathrm{MeCN}$ & $\mathrm{DMF}$ & $\mathrm{PhCl}$ & $\mathrm{DMAc}$ \\
\hline PMeOx & + & + & - & $+-^{\mathrm{a}}$ & & - & + \\
PEtOx & LCST & + & + & + & + & + & + \\
Pn-PrOx & LCST & + & + & + & & + & + \\
Pn-NonOx & - & & + & - & - & & + \\
PPhOx & - & & + & + & + & & + \\
Pc-BuOx & - & - & & $+/-^{\mathrm{b}}$ & & $+/-^{\mathrm{b}}$ & $+/-^{\mathrm{b}}$ \\
Pc-PentOx & - & - & & - & & - & - \\
Pc-HexOx & - & - & & - & & $+/-^{\mathrm{c}}$ & $+/-^{\mathrm{c}}$ \\
\hline
\end{tabular}

${ }^{a}$ poor solubility for molar mass $>\sim 20 \mathrm{kDa},{ }^{b}$ soluble after heating, precipitated on cooling. ${ }^{\mathrm{c}}$ soluble after heating 